\title{
Lung Phospholipids in the Embryonic and Immature Chicken: Changes in Lipid Composition and Biosynthesis During Maturation of the Surfactant System
}

VINCENT W. HYLKA AND BYRON A. DONEEN

Division of Biological Sciences, Department of Zoology, University of Michigan, Ann Arbor, Michigan 48109

\begin{abstract}
Total phospholipid and its components were measured in lungs of the embryonic chick, and in tissue, lamellar bodies, and lavage fluid after hatching. Phosphatidylcholine (PC), the major phospholipid in surfactant, was fractionated and the amount and fatty acid composition of its disaturated (DSPC) component was determined. The synthetic rates of PC, DSPC, and other choline phospholipids were determined on days 14 and 19 of incubation from incorporation of ${ }^{14} \mathrm{C}$-choline. Choline pool size was also estimated at these times. Phospholipid content of the lung increased most rapidly after day 18 of incubation with the greatest increase in PC. The PC synthesized just prior to breathing was enriched in DSPC, which constituted $45 \%$ of PC on day 19 and only $30 \%$ on day 14 . DSPC content was even lower in embryonic liver and yolk. Incorporation of ${ }^{14} \mathrm{C}$-choline in vitro into pulmonary PC, Sphingomyelin (Sphingo), and DSPC was greater in birds before breathing (day 19) than in the younger embryos. Choline pool size decreased between days 14 and 19 of incubation, but the synthetic rate of DSPC doubled in this interval. Increased accumulation and biosynthesis of pulmonary PC, Sphingo, and DSPC in lung tissue of the embryo paralleled appearance of lamellar bodies. In 5-6-week-old chickens the major pulmonary phospholipid was also DSPC. In lavage, $70 \%$ of PC was DSPC, predominantly dipalmitoyl PC. As in the mammalian lung, PC, especially its DSPC component, forms the major phospholipid of avian surfactant, and the synthesis of DSPC is specifically stimulated prior to breathing.
\end{abstract}

The gas-exchanging surface of the mammalian lung is lined with surfactant. By lowering surface tension, surfactant prevents alveolar collapse, reduces work expended in lung expansion, and inhibits transudation of fluid into air spaces (Levine and Mellins, '75; Van Golde, '76). Mammalian lung surfactant consists largely of phospholipid $(85 \%$ by weight), and this is predominantly $(70-80 \%)$ phosphatidylcholine (PC) (Rooney, '79). The major surface-active component of surfactant is dipalmitoyl PC (containing two 16:0 fatty acids), which forms $60-70 \%$ of $P C$ in lung lav. age (Van Golde, '76). Lung surfactant is synthesized and stored in lamellar bodies, organelles characteristic of type II pneumocytes (Williams, '77). Maturation of the type II cell as measured by its capacity to synthesize and secrete surfactant phospholipid, depends upon certain hormones (reviewed by Smith and Bogues, '80; Hitchcock, '80; Ballard '81).

As air capillaries in the avian lung are strengthened by connective tissue (Duncker, 71), this structure is more rigid than the mammalian lung. The bird lung, therefore, might appear to have little requirement for a surfaceactive lining. Ultrastructural examination, however, revealed an osmiophilic lining in air spaces of the chicken, goose, and turkey (Tyler and Pangborn, '64; Lambson and Cohn, '68; Petrik and Riedel, '68a, b; Fujiwara et al., '70). This lining seems to be quite similar in biochemistry and in function to mammalian surfactant. Composition of major pulmonary 
phospholipids in the adult bird is nearly identical with mammalian lung (Harlan et al., '66; Fujiwara et al., '70). Lung lavages from adult birds contain secreted surfactant, and these washings display a lipid composition and surface tension properties similar to those of mammals (Fujiwara et al., '70). Lamellar bodies have also been identified in type II pneumocytes of the avian pulmonary epithelium (Dameron and Marin, '70; Marin et al. '78), and these organelles are enriched in PC (Marin et al., '79). Pattle ('65, '78) and Duncker ('71, '78) have proposed that structural rigidity of avian lung and pulmonary surfactant both promote distention of narrow air capillaries. Thus, appearance of surfactant in the embryonic bird lung prior to the onset of ventilation may be as crucial for hatching as it is for the birth of mammals.

The work of Tordet and Marin ('76) on the embryonic chicken lung has emphasized the ontogeny of two major classes of lung phospholipids, $\mathrm{PC}$ and phosphatidylethanolamine (PE). These investigators (Marin et al., '79) also showed that PC content was enriched in avian lung lavage and isolated lamellar bodies. In both studies, the major surface-active component of PC (i.e., DSPC) and other minor, though important, surfactant lipids (i.e., phosphatidylglycerol:PG, phosphatidylinositol:PI, and Sphingomyelin: Sphingo) were not measured. Earlier work has also shown that incorporation of ${ }^{14} \mathrm{C}$-choline into $\mathrm{PC}$ increases in the bird lung prior to hatching (Compton and Goeringer, '81), but the significance of this conclusion must be questioned because the size and specific activity of the pulmonary choline pool were not determined during ontogeny. Finally, no data are available to determine if lipid composition and certain pathways of phospholipid synthesis are unique to the developing lung as seems to be the case in the mammal (Van Golde, '76). This information is essential in view of the totally different pattern of fat metabolism in the avian embryo which relies ultimately on stored yolk for lipid precursors (Doneen, '81). This paper fills major gaps in our understanding of lung lipid metabolism in the developing bird lung by presenting a more complete analysis of lung phospholipids (including DSPC) in the chick during development. It also reports the distribution of DSPC in embryonic lung, liver, and yolk, and in lavage and isolated lamellar bodies from breathing chickens. Finally, we have determined actual rates of biosynthesis of pulmonary PC and DSPC early in incubation and before onset of ventilation, taking account of differences in choline pool size.

\section{MATERIALS AND METHODS}

\section{Animals}

Fertilized eggs (Rhode Island Red $\times$ White Leghorn) were obtained from a local distributor (Dave's Eggs and Poultry, Ann Arbor, Michigan), and incubated at $37.7 \pm 0.7^{\circ}$ in a forced-draft, rocking incubator. Hatched birds were kept on a 12D:12L cycle and fed commercial poultry feed and water ad libitum. Onset of breathing in embryos was determined by observing whether pipping had occurred or if the beak was in the air space. In this study, all embryos at 20 days of incubation had begun lung ventilation, whereas those at 19 days or younger had not commenced breathing.

\section{Lipid isolation and analysis}

Tissues were rapidly dissected, blotted, weighed, and quick-frozen in a dry-ice-ethanol bath. Yolk was obtained by pipetting a $300 \mu \mathrm{l}$ aliquot from the yolk sac, being careful to avoid blood contamination. Tissues and yolk were stored at $-25^{\circ} \mathrm{C}$ until analyzed.

Total lipids were extracted by homogenization with 20 volumes of chloroform:methanol (2:1) according to the method of Folch et al. ('57). Total extracted fat was measured gravimetrically following evaporation of solvent and overnight desiccation in vacuo over $\mathrm{KOH}$. In experiments involving choline incorporation, an aliquot of the chloroform:methanol homogenate was used for measurement of protein using bovine serum albumin as standard (Lowry et al., '51).

Individual phospholipid classes were obtained by thin-layer chromatography (TLC) using Whatman LK5D precoated silica gel plates. Lipid samples (500-900 $\mu \mathrm{g}$ ) were applied to TLC plates in a nitrogen atmosphere with standards run in parallel. Phospholipids were separated using chloroform:methanol:water (65:35:5, solvent system I) or chloroform:methanol: $0.25 \% \mathrm{KCl}: 2$-propanol:triethylamine $(30$ : 9:6:25:18, solvent system II) (Touchstone et al., '80). Solvent system II was utilized for better separation of PE from PG, and of phosphatidylserine (PS) from PI. Phospholipids were identified on TLC plates by comparision with standards after staining with iodine vapor (solvent system I), or from UV fluorescence after heating plates $\left(1 \mathrm{~h}\right.$ at $180^{\circ} \mathrm{C}$, solvent system II). Individual phospholipids were scraped from TLC plates into glass-stoppered tubes, and eluted at $55^{\circ} \mathrm{C}$ in ethanol:chloro- 
form:water:acetic acid (100:30:20:2) (Biezenski, '64). Recoveries ranged from $95 \%$ to $99 \%$. Lipid phosphorous in individual phospholipids and extract was determined according to Bartlett ('59) after digestion with $400 \mu \mathrm{l}$ of $72 \%$ perchloric acid for $1 \mathrm{~h}$ at $220^{\circ} \mathrm{C}$. Saturated phospholipids were isolated according to the procedure of Mason et al. ("76). Approximately $1 \mathrm{mg}$ of lipid was reacted with $500 \mu \mathrm{l}$ of 6.2 $\mathrm{mg} / \mathrm{ml} \mathrm{OsO} \mathrm{O}_{4}$ in $\mathrm{CCl}_{4}$; saturated neutral and phospholipids were separated using column chromatography (neutral alumina; BioRad, AG7, 100-200 mesh). Saturated phospholipids were further separated by TLC using solvent system II. Recovery of DL- $\alpha$-dipalmitoyl phosphatidylcholine standard (Sigma) from column and thin-layer chromatography was $96-98 \%$.

Fatty acid composition of pulmonary DSPC isolated from 5-week-old chickens was determined by gas chromatography after transesterification using sodium methoxide and benzene (Luddy et al., '60). Methylated fatty acids were extracted with diethylether and dried before chromatography. Peak areas were measured using an electronic integrator. The minimum amount of DSPC that contained two palmitic acid moieties (dipalmitoyl PC) was calculated as the difference in mole percent of total nonpalmitic acids and mole percent of palmitic acid.

\section{Lung lavage}

Lungs were obtained from 5-week-old chickens sacrificed by a blow to the head. Lungs (minus air sacs) were excised, washed externally with $0.9 \%$ saline, and detached from the trachea. Each lung was lavaged with $25 \mathrm{ml}$ of $0.9 \%$ saline (introduced 4-5 times via primary bronchus) collected from a superficial cut made in the posterior area of the lung. The same solution was used to wash three lung pairs. Ninety percent of the introduced fluid was recovered, and this was centrifuged at $300 \mathrm{~g}$ for $10 \mathrm{~min}\left(4^{\circ} \mathrm{C}\right)$. The surfacant fraction of lung wash was isolated from the supernatant obtained after centrifugation at $2,000 \mathrm{~g}$ according to Fujiwara et al. ('70), and lipids were isolated as described.

\section{Lamellar body isolation}

Lungs were dissected from 6-week-old chickens, minced, washed in homogenization buffer $10.25 \mathrm{M}$ sucrose, $0.05 \mathrm{M}$ Tris- $\mathrm{HCl}, \mathrm{pH}$ $7.05)$, and homogenized $(10 \mathrm{ml}$ buffer per $\mathrm{g}$ wet weight) with 6-7 slow passes of a tight fitting Telfon pestle. The homogenate was filtered through cheesecloth, and the $13,000 \mathrm{~g}$ pellet prepared as previously described (Heath and Jacobson, '76). The twice-washed pellet was diluted to $8.5 \mathrm{ml}$ with homogenization buffer, one half layered onto $8.5 \mathrm{ml}$ of $0.75 \mathrm{M}$ sucrose, $0.05 \mathrm{M}$ Tris-Hcl, $\mathrm{pH} 7.05$, and centrifuged at $90,000 \mathrm{~g}$ for $2.8 \mathrm{~h}$. The material located at the $0.25-0.75 \mathrm{M}$ sucrose interface was collected, diluted to $10 \mathrm{ml}$ with homogenization buffer, and centrifuged at $10,000 \mathrm{~g}$ for $30 \mathrm{~min}$. The resulting pellet was resuspended in $8 \mathrm{ml}$ of $0.154 \mathrm{M} \mathrm{KCl}$ and centrifuged at $20,000 \mathrm{~g}$ for 30 min. Portions of this final pellet (lamellar bodies), as well as the more dense pellet obtained by centrifugation at $90,000 \mathrm{~g}$, were fixed for electron microscopy. The remaining material was frozen at $-25^{\circ} \mathrm{C}$ and analyzed for lipids as described.

\section{Electron Microscopy}

Subcellular fractions from 6-week chicken lungs were fixed in 1 part $2.5 \%$ glutaraldehyde +2 parts $1 \% \mathrm{OsO}_{4}$ in $0.1 \mathrm{M}$ cacodylate buffer, $\mathrm{pH} 7.4$, at $0^{\circ} \mathrm{C}$ for $1 \mathrm{~h}$ (Hirsch and Fedorko, '68). Samples were postfixed in $0.25 \%$ uranyl acetate, dehydrated in a series of increasing alcohol concentrations, and embedded in polybed 812 (Polysciences). Sections were stained en grid with uranyl acetate and lead citrate, and viewed with a Phillips 300 electron microscope.

\section{Choline incorporation}

Lungs dissected from day 14 and day 19 embryos were sliced into cubes $\left(\mathrm{ca} .2 \mathrm{~mm}^{3}\right.$ ) and transferred to $0.5 \mathrm{ml}$ of medium 199 with Earl's salts (GIBCO) which contained $1 \mu \mathrm{Ci}$ ${ }^{14} \mathrm{C}$-choline chloride (New England Nuclear; specific activity in culture media $=45.5$ $\mathrm{mCi} / \mathrm{mmole})$. Each incubation vessel contained 100-200 $\mathrm{mg}$ of tissue ( $15 \mathrm{mg}$ protein). Tissues from individuals were incubated separately at $37.7 \pm 0.7^{\circ} \mathrm{C}$. To terminate incorporation, tubes were placed in ice and tissues washed twice with ice-cold $0.9 \%$ saline. Tissues were quick-frozen in a dry-ice-ethanol bath and stored at $-25^{\circ} \mathrm{C}$. Lipids were extracted and separated as described. Radioactivity in phospholipids was determined by scraping TLC gel into scintillation vials containing 10 ml scintillation fluid (OCS, Amersham). The channels ratio method was used to calculate counting efficiencies.

Lung choline content was measured by slight modification of the enzymatic method of Shea and Aprison ('73). Choline was extracted in ice-cold $15 \%$ formic acid in acetone, and lipids were removed with a heptane:chloroform (8:1) wash. Choline was converted to ${ }^{3} \mathrm{H}$-acetyl- 
choline using $6 \mathrm{U} / \mathrm{ml}$ choline acetyl transferase (Sigma) with ${ }^{3} \mathrm{H}$-acetyl CoA ( $30 \mathrm{mCi} / \mathrm{mmole}$ ) as acetate donor. Radioactivity in the labeled product was determined after its extraction with tetraphenylboron in allyl cyanide. All samples and standards were run in triplicate. Choline content was expressed as nanomoles/mg tissue protein. Specific activity of choline was measured as the ratio of ${ }^{14} \mathrm{C} \mathrm{dpm}$ in tissue to total tissue choline (endogenous plus choline taken up from medium) at the end of the incubation period.

\section{Statistics}

Best-fit regression lines and correlation coefficients were calculated using the least-squares method. Differences in choline uptake and lung phospholipid content were determined using Student's $t$ test. In cases of unequal variance, the adjusted $t$ test was employed (Bhattacharyya and Johnson, '77).

\section{RESULTS}

Table 1 shows total lipid and phospholipid in the lung of the chick embryo from days 14-21 of incubation. Lipid content of the lung in creased at a fairly uniform rate throughout embryogenesis. Pulmonary phospholipid accumulated steadily until 18 days of development, after which the accretion rate became elevated. Phospholipid comprised about $52 \%$ of total lipid on days 14-18 of incubation, but on day 19 and thereafter increased to $61-65 \%$ of the lipid.

Ontogeny of pulmonary phospholipid components are shown in Figure 1. The major lung phospholipid throughout incubation was PC. The rate of PC accumulation was somewhat higher than other phospholipids before day 18 . After 18 days of incubation, pulmonary PC and also Sphingo increased even more rapidly than other components. In the measurements shown in Figure 1, PE was not separated from PG, and PI was not separated from PS. By use of solvent system II (see Methods) it was possible to separate all lipid classes. In one such experiment the distribution of phospholipids in the lung of 18-day embryos was $\mathrm{PC}-45 \%$ of total phospholipid, Sphingo-13\%, PE-9\%, PS $-9 \%$, PI $-6 \%$, lysophosphatidylcholine (Lyso PC) $-5 \%$, and $\mathrm{PG}-4 \%$.

Lung, liver, and yolk of the embryonic chick were assayed for PC and DSPC (Table 2). PC formed $44 \%$ of total phospholipid in lungs of day 14 and day 19 embryos. However, the contribution of pulmonary DSPC to total PC increased from $29.5 \%$ on day 14 to $44.6 \%$ on day 19 of incubation $(\mathrm{P}<0.005)$. Although $\mathrm{PC}$ in
$T A B L E$ 1. Total lipid and phospholipid content in the lung of the embryonic chick from days 14-21 of incubation $^{a}$

\begin{tabular}{ccc}
\hline & \multicolumn{2}{c}{ Lung pair (mg) } \\
\cline { 2 - 3 } Days of incubation & Lipid & Phospholipid \\
\hline 14 & $1.52 \pm 0.16$ & $0.80 \pm 0.10$ \\
16 & $3.14 \pm 0.30$ & $1.62 \pm 0.10$ \\
18 & $4.50 \pm 0.26$ & $2.38 \pm 0.15$ \\
19 & $5.39 \pm 0.29$ & $3.30 \pm 0.25$ \\
20 & $6.77 \pm 0.35$ & $4.32 \pm 0.28$ \\
21 & $7.45 \pm 0.44$ & $4.87 \pm 0.34$ \\
\hline
\end{tabular}

${ }^{a}$ All values expressed as mean \pm standard error. $\mathrm{N}=8-11$ paired lungs.

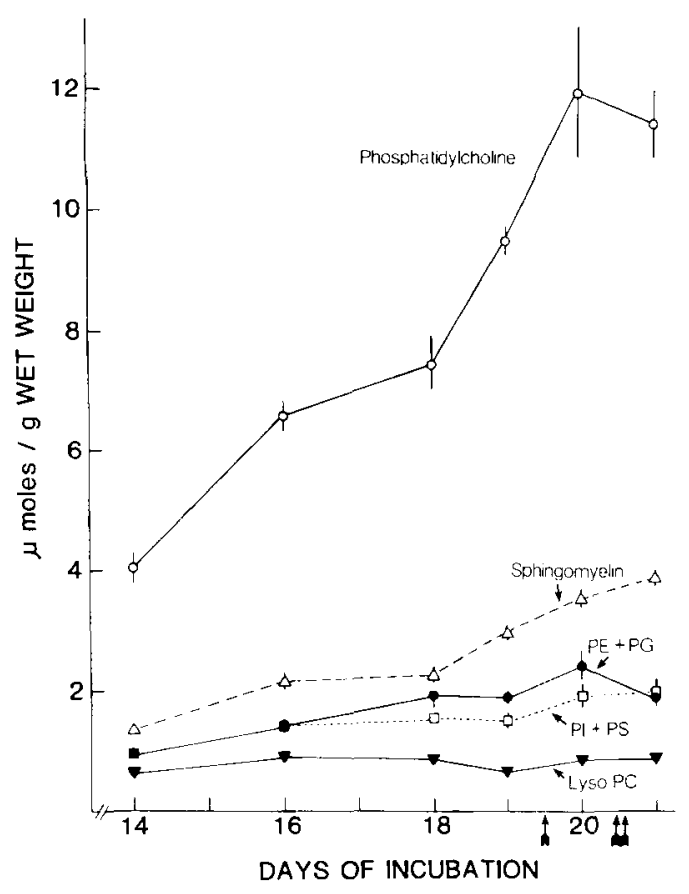

Fig 1. Ontogeny of pulmonary phospholipid components in the chick embryo. Values are mean \pm standard error (vertical lines). $\mathrm{N}=6-14$ individual samples. The single arrow marks the onset of lung ventilation. The double arrows denote time of hatching. Symbols: Lyso PC-lysophosphatidylcholine; PE + PG-pooled phosphatidyleth anolamine and phosphatidylglycerol; PI + PS - pooled phosphatidylinositol and phosphatidylserine.

day 19 liver (42\% of phospholipids) and 17-day yolk $(46 \%)$ were comparable to fractional PC content in the embryonic lung, the contribution of DSPC to PC was significantly reduced in these tissues $(14 \% ; \mathrm{P}<0.005)$ compared with lung.

Phospholipid composition of tissue, lavage, and isolated lamellar bodies from lungs of im- 
TABLE 2. Phosphatidylcholine (PC) and disaturated phosphatidylcholine (DSPC) in some tissues of the embryonic chick ${ }^{a}$

\begin{tabular}{|c|c|c|c|c|c|}
\hline \multirow[b]{2}{*}{ Tissue } & \multirow[b]{2}{*}{ Day of incubation } & \multicolumn{2}{|c|}{$\begin{array}{c}\text { PC: As a \% of } \\
\text { total phospholipid }\end{array}$} & \multicolumn{2}{|c|}{$\begin{array}{c}\text { DSPC: As a \% of } \\
\text { Phosphatidylcholine }\end{array}$} \\
\hline & & $(\mathrm{N})$ & & (N) & \\
\hline Lung & 14.0 & $(22)$ & $44.7 \pm 0.7$ & (14) & $29.5 \pm 0.9$ \\
\hline Lung & 19.0 & (22) & $44.0 \pm 1.2$ & (15) & $44.6 \pm 1.4^{b}$ \\
\hline Liver & 19.0 & (5) & $42.3 \pm 1.7$ & (5) & $14.0 \pm 2.5^{\mathrm{c}}$ \\
\hline Yolk & 17.0 & (3) & $46.2 \pm 1.5$ & (3) & $14.5 \pm 1.5^{c}$ \\
\hline
\end{tabular}

${ }^{8}$ All values are mean \pm standard error. $N=$ number of samples.

${ }^{b}$ Significantly different from DSPC values for 14-day lung $(\mathrm{P}<0.005)$.

${ }^{c}$ Significantly different from DSPC values for 19-day or 14-day lung $(P<0.005)$.

TABLE 3. Phospholipid composition of lung tissue, lamellar body, and lavage in immature (5-6-week old) chickens ${ }^{\mathrm{a}}$

\begin{tabular}{|c|c|c|c|}
\hline Phospholipids & $\begin{array}{l}\text { Lung tissue } \\
(\mathbf{N}=4)^{\mathrm{b}}\end{array}$ & $\begin{array}{c}\text { Isolated lamellar } \\
\text { bodies }(\mathrm{N}=3)\end{array}$ & $\begin{array}{l}\text { Lung lavage } \\
(\mathrm{N}=4)\end{array}$ \\
\hline $\begin{array}{l}\text { Phosphatidylcholine } \\
\text { Phosphatidylethanolamine } \\
\text { Sphingomyelin } \\
\text { Phosphatidylserine } \\
\text { Phosphatidylinositol } \\
\text { Phosphatidylglycerol } \\
\text { Lysophosphatidylcholine }\end{array}$ & $\begin{array}{r}37.8 \pm 1.2 \\
20.2 \pm 0.6 \\
12.0 \pm 0.5 \\
10.6 \pm 0.6 \\
7.3 \pm 0.4 \\
3.3 \pm 0.7 \\
3.2 \pm 0.9\end{array}$ & $\begin{array}{r}64.4 \pm 2.2 \\
5.2 \pm 0.4 \\
0.9 \pm 0.1 \\
3.2 \pm 0.3 \\
7.9 \pm 0.2 \\
0.8 \pm 0.2 \\
0.4 \pm 0.1\end{array}$ & $\begin{array}{r}76.8 \pm 6.5 \\
3.8 \pm 1.2 \\
4.0 \pm 1.4 \\
0.5 \pm 0.4 \\
8.7 \pm 1.6 \\
<0.1 \\
1.6 \pm 1.0\end{array}$ \\
\hline $\begin{array}{l}\text { Dissaturated phosphatidylcholine } \\
\text { (As a\% of total phospholipids) } \\
\text { (As a \% of phosphatidylcholine) }\end{array}$ & $\begin{array}{l}20.6 \pm 0.6 \\
54.4 \pm 2.1\end{array}$ & $\begin{array}{l}37.4 \pm 0.7 \\
58.2 \pm 2.2\end{array}$ & $\begin{array}{l}53.3 \pm 10.4 \\
70.0 \pm 9.3\end{array}$ \\
\hline
\end{tabular}

${ }^{a}$ All values expressed as a $\%$ of total lipid phosphorous \pm SEM.

$\mathrm{b}_{\mathrm{N}}=$ number of samples. Each lamellar body sample was prepared from six paired lungs. Each lavage sample was obtained from three pooled pairs of lungs (see Methods).

mature (5-6 week) chickens is presented in Table 3. Figure 2 shows an electron micrograph of the isolated lamellar body fraction, and confirms that it was highly enriched in lamellar bodies, most of which appeared structurally intact. Ultrastructural observation of the $90,000 \mathrm{~g}$ pellet revealed no identifiable lamellar bodies (data not shown). In the juvenile chicken, PC was the major phospholipid component of lung tissue, lavage, and lamellar bodies (Table 3). PC was more abundant in lung wash $(77 \%$ of total phospholipid and the lamellar body fraction $(64 \%)$ than in lung tissue $(38 \%)$ (Table 3.) Lung lavage contained the highest fractional DSPC content (70\% of PC) with DSPC content in lamellar bodies $(58 \%)$ and tissue $(54 \%)$ somewhat lower. Thus, PC and DSPC increased in going from lung tissue to lavage, whereas the contribution of most other phospholipids decreased. The only exception was PI, which uniformly formed 7-9\% of phospholipids in tissue, lamellar bodies, and lavage.

Fatty acid composition of DSPC isolated from the juvenile lung is presented in Table 4. Over $92 \%$ of the fatty acids in DSPC were palmitic (16:0), with myristic (14:0) and stearic
(18:0) being the next most abundant $(2.5 \%$ each). At minimum, $85 \%$ of DSPC was dipalmitoyl PC.

The rates of ${ }^{14} \mathrm{C}$-choline incorporation into PC, Sphingo, Lyso PC, and DSPC in lung slices of day 14 and day 19 chick embryos are given in Table 5. Results presented in Figure 3 illustrate that incorporation of label into DSPC in vitro was linear for $6 \mathrm{~h}$. Linearity of incorporation rate was also observed for the other phospholipids. Compared with 14-day embryos, the lungs of 19-day embryos incorporated significantly more ${ }^{14} \mathrm{C}$-choline into $\mathrm{PC}$, Sphingo $(\mathrm{P}<$ 0.05 ), and into DSPC (P $<0.005$ ), but not into Lyso PC. The rates of incorporation of ${ }^{14} \mathrm{C}$ choline into saturated Lyso PC and saturated Sphingo were also not significantly different in day 14 and day 19 lung (data not shown). In the day 19 lung, average distribution of radioactivity among the choline phospholipids was $83 \%$ in PC, $11 \%$ in Lyso PC, and 6\% in Sphingo. Distribution of label among the saturated choline phospholipids was DSPC: 93\%; saturated Lyso PC: $4 \%$; saturated Sphingo: 3\%. Calculations using data in Table 5 also show that $41 \%$ of the labeled PC was composed of newly synthesized ${ }^{14} \mathrm{C}$-DSPC in the 19-day lung, whereas 


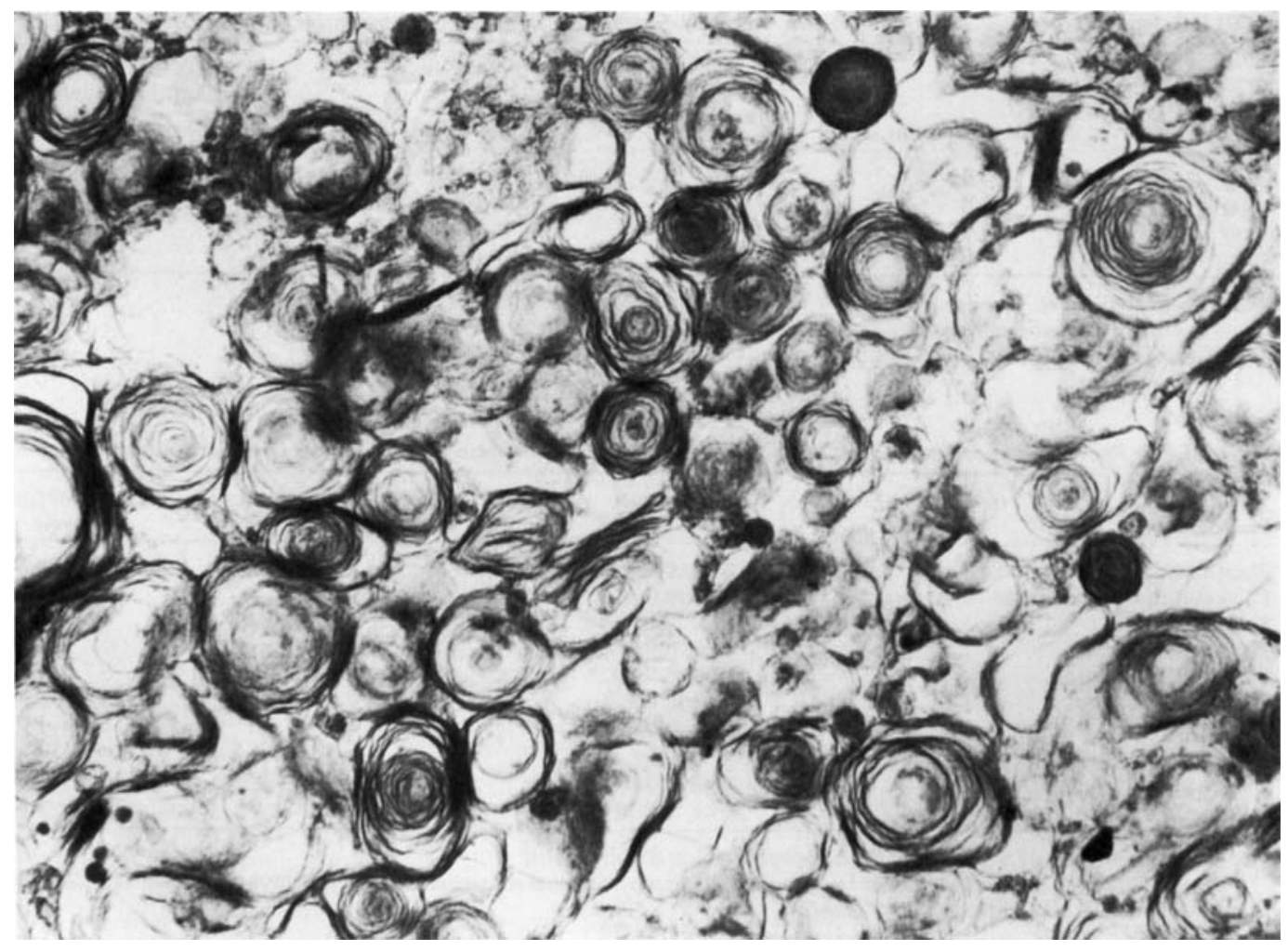

Fig. 2. Lamellar bodies isolated from 6-week chicken lungs $(\times 16,000)$. Note that most lamellar bodies appear to be intact.

TABLE 4. Fatty acid composition of dissaturated phosphatidylcholine in 6-week-old chicken lunga

\begin{tabular}{crrrrrr}
\hline $\begin{array}{l}\text { Fatty } \\
\text { acids }^{\mathrm{b}}\end{array}$ & $14: 0$ & $15: 0$ & $16: 0$ & $18: 0$ & $18: 1$ & Unidentified \\
\hline & 2.5 & 0.6 & $92.3^{\mathrm{c}}$ & 2.7 & 1.2 & 0.9 \\
\hline
\end{tabular}

a All values are the means of duplicate samples from four lungs, and are expressed as mole \%.

${ }^{b}$ Fatty acids are represented as number of carbon atoms:double bonds.

${ }^{\mathrm{c}}$ Minimum dipalmitoyl phosphatidylcholine $=84.6 \%$ of dissaturated phosphatidylcholine (see Methods).

only $21 \%$ of the de novo synthesized $\mathrm{PC}$ was formed by ${ }^{14} \mathrm{C}$-DSPC in day 14 lung slices. In order to determine the actual synthetic rate of these phospholipids the choline pool size and its specific activity must be known. Choline content was determined in lungs of day 14 and day 19 embryos (Table 6). Choline (normalized to tissue protein) declined by $53 \%$ between days 14 and 19 of incubation. Choline was also measured in lung slices in the in vitro incorporation experiment. Its concentrations in days 14 and 19 lungs were similar to those shown in
Table 6 and were used to calculate specific activities of tissue choline pools. These values appear in Table 5 along with the actual synthetic rates of the choline-containing lipids. These calculations reveal a marked elevation in pulmonary PC synthesis, especially in its DSPC component, in the day 19 lung. Sphingo synthesis was also elevated in the day 19 lung, whereas synthesis of Lyso PC was significantly $(\mathrm{P}<0.05)$ depressed from the day 14 level.

\section{DISCUSSION}

\section{Pulmonary lipids}

Mammalian surfactant is enriched in PC (King, '74), and accumulation of this phospholipid, especially its DSPC component, in fetal lung, parallels differentiation of type II cells and biochemical pathways of surfactant synthesis. Our paper extends previous results by showing several biochemical similarities in ontogeny of pulmonary lipids in mammals and birds. As in mammals, the lung of the embryonic chicken was rich in phospholipid, which 
TABLE 5. Rate of incorporation of ${ }^{14}$ C.choline in vitro into phosphatidylcholine, dissaturated phosphatidylcholine, sphingomyelin and lysophophatidylcholine, in lung slices of day 14 and day 19 chicken embryos ${ }^{a}$

\begin{tabular}{|c|c|c|c|c|}
\hline \multirow[b]{2}{*}{ Phospholipid } & \multicolumn{2}{|c|}{$\begin{array}{l}\text { dpm Incorporated/g } \\
\text { protein } / \mathrm{h}^{\left(\times 10^{2}\right)}\end{array}$} & \multicolumn{2}{|c|}{$\begin{array}{c}\text { Nanomoles synthesized/g } \\
\text { protein/hb }\end{array}$} \\
\hline & Day 14 & Day $\overline{19}$ & Day 14 & Day 19 \\
\hline Phosphatidylcholine & $420.0 \pm 35.0$ & $632.5 \pm 35.0$ & $2.91 \pm 0.23$ & $3.62 \pm 0.20^{c}$ \\
\hline Dissaturated phosphatidylcholine & $87.5 \pm 7.5$ & $257.5 \pm 17.5$ & $0.61 \pm 0.07$ & $1.49 \pm 0.10^{\mathrm{d}}$ \\
\hline Sphingomyelin & $25.0 \pm 2.5$ & $55.0 \pm 5.0$ & $0.16 \pm 0.02$ & $0.32 \pm 0.03^{c}$ \\
\hline Lysophosphatidylcholine & $80.1 \pm 7.5$ & $72.5 \pm 5.0$ & $0.54 \pm 0.07$ & $0.42 \pm 0.03^{c}$ \\
\hline
\end{tabular}

${ }^{\text {a }}$ alues are expressed as mean \pm standard error of 4-5 individual samples. In vitro incubation time: $4 \mathrm{~h}$. Samples contained $50-3,250 \mathrm{cpm}$ above background and were counted to $2 \%$ counting error.

${ }^{b}$ Calculated from the choline specific activity determined in tissue slices. Specific activity of choline pool (expressed as dpm/nmole) was $1.445 \pm 0.035 \times 10^{4}$ for day 14 and $1.750 \pm 0.028 \times 10^{4}$ for day 19 lung slices.

'Significantly different from mean values for day 14 lung slices $(P<0.05)$.

${ }^{\mathrm{d}}$ Significantly different from mean values for day 14 lung slices $(P<0.005)$.

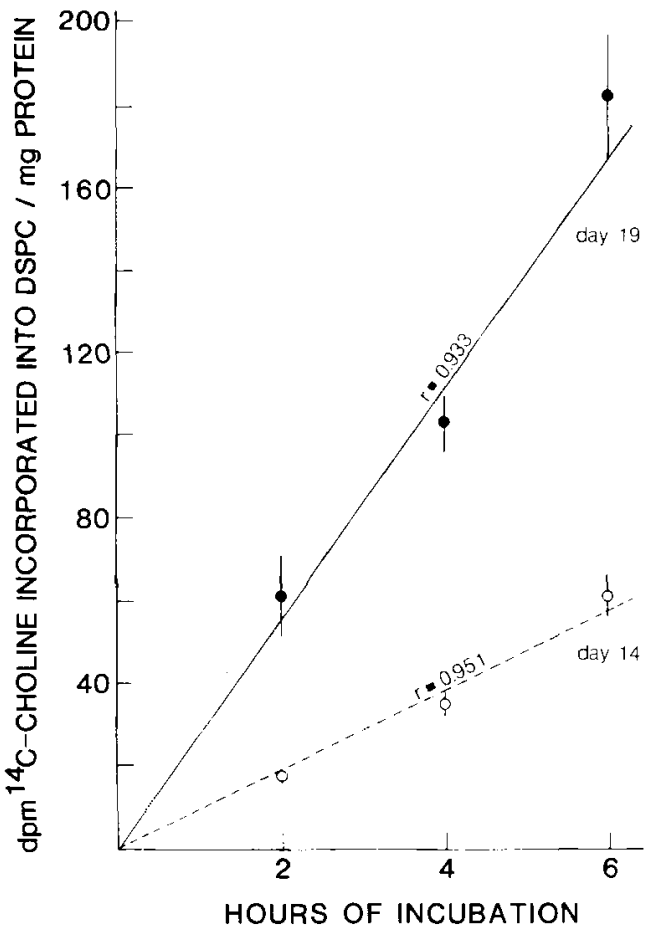

Fig. 3. Rate of incorporation of ${ }^{14} \mathrm{C}$-choline in vitro into dissaturated phosphatidylcholine (DSPC) in lung slices of day 14 and day 19 embryos. Values are means \pm standard errors (vertical lines). $\mathrm{N}=4$ or 5 samples. Incorporation was linear for $6 \mathrm{~h}$. Slices were incubated in medium 199 at $37.7^{\circ} \mathrm{C}$. Correlation coefficients of regression lines denoted by $\mathrm{r}$.

constituted $52 \%$ of pulmonary lipid before day 19 of incubation but exceeded $60 \%$ thereafter (Table 1; Tordet and Marin, '76). The major elevation in total phospholipid began on day 18 of incubation, 1.5 days prior to onset of breathing (Table 1). PC was the major pulmonary phospholipid throughout development in the
$T A B L E$ 6. Concentrations of choline in the lung of the embryonic chicken

\begin{tabular}{cc}
\hline Day of incubation & Nanomoles choline/mg protein \\
\hline 14 & $2.26 \pm 0.16$ \\
19 & $1.21 \pm 0.09^{\mathrm{b}}$ \\
\hline
\end{tabular}

${ }^{a}$ All values are expressed as mean \pm standard error: $N=6$. ${ }^{b}$ Significantly different from day 14 lungs $(P<0.005)$.

chicken lung, followed by Sphingo and PE. Elevated phospholipid accumulation after day 18 was predominantly in $\mathrm{PC}$, and to a lesser extent, Sphingo, whereas other phospholipids remained constant (per unit wet weight, Fig. 1). Increased tissue PC after day 18 can probably be attributed to lamellar bodies, whose principle component was PC (Table 3; Marin et al., '79), and which undergo accelerated differentiation at this time (Marin et al., '78; Hylka, unpublished). Increased pulmonary Sphingo observed in late incubation of the embryonic chicken (Fig. 1) does not appear to be located in lamellar bodies, since isolated lamellar bodies and lavage derived from the posthatch chicken contain little Sphingo (Table 3). However, avian lungs possess a second, apparently novel type of surfactant, termed trilaminar substance (TLS) (Pattle, '78). This material can be distinguished ultrastructurally from lamellar bodies, is present in the lung during the final days of incubation and in the newly hatched chick, but disappears upon further maturation (Pattle, '78; Hylka, unpublished). Although isolation and chemical analysis of TLS have not been done, one possibility is that TLS is enriched in Sphingo, which could account for its transitory elevation at the end of incubation.

The contributions of various phospholipids to total lung phospholipid in the juvenile bird were generally similar to that in the embryonic 
lung. PC content was reduced somewhat in the juvenile ( $38 \%$ of total phospholipid; Table 3) compared with the embryo. Results in Tables 2, 3, and 4 show that a large percentage of lung PC was DSPC (especially dipalmitoyl PC). Thus, the increased saturated fatty acid content in lung PC observed in late incubation by Tordet and Marin ('76) can now be assigned to DSPC. The fractional contribution of DSPC to $\mathrm{PC}$ increased most rapidly in embryonic lungs just prior to onset of ventilation (Table 2). The DSPC content of PC rose even higher in the juvenile (Table 3 ). Although other lipid-rich embryonic and extraembryonic tissues contained DSPC, it constituted only one-third as much of the PC in liver and yolk (Table 2) as in lung. Whereas embryonic yolk or liver could serve as a source of DSPC for lung surfactant formation, incorporation studies discussed below prove that the lung has the capacity for de novo synthesis of DSPC.

Content of various phospholipids in the later days of incubation and 5-6 weeks after hatching measured in this study agree with published results on the adult avian lung (Harlan et al., '66) but differ in one respect from earlier work in the embryonic chicken. Tordet and Marin ('76) observed that PE formed 30-40\% of total pulmonary phospholipid, a value considerably higher than the $9 \%$ found on day 18 of incubation and the $20 \%$ observed in the juvenile (Table 3 ) and adult (22\%) (Harlan et al., '66) chicken lung. The description of lipid isolation and characterization by Tordet and Marin ('76) lacked the necessary detail for us to evaluate methodological differences as a possible basis for these discrepancies.

In isolated lamellar bodies and in lavage fluid, PC and DSPC content were greater than in whole lung (Table 3 ), which suggests that the secreted lipid was enriched specifically in these components. PC and DSPC content in chicken lamellar bodies and lung washings were quantitatively similar to these same fractions in the mammalian lung (Van Golde, '76). On the other hand, washings from the avian lung contained greater quantities of PI (Table 3) than mammalian lungs (Van Golde, '76). It is important to identify phospholipids whose relative content increases with purification, since this identifies the most important surfactant components. The fact that isolated lamellar bodies do not have the same phospholipid distribution as lipid from lavaged airways could be a) due to failure to obtain a pure lamellar body preparation; b) due to isolation of lamellar bodies at various stages of maturation, some fraction having a composition resembling tissue, and others having a phospholipid profile closer to secreted surfactant; or c) that after secretion, lipids in lamellar bodies undergo further biochemical transformation in the airways. The first possibility can be eliminated by the ultrastructural evidence for a highly purified lamellar body fraction (Fig. 2). Thus, maturation of lamellar bodies seems to be associated with progressively increased PC and DSPC content, retention of a nearly constant fractional contribution by PI, and with decreased contributions from other phospholipids.

\section{Choline incorporation into phospholipids of embryonic lung slices}

The incorporation study showed that 14- and 19-day embryonic lungs were capable of synthesizing major and minor surfactant lipids in vitro. The rate of choline incorporation into $\mathrm{PC}$ and Sphingo was greater in lungs of embryos just prior to breathing (Table 6). The parallel increase in lung PC and Sphingo content (Fig. 1) and synthetic rate (Table 6) during development may reflect stimulation of the cytidyldiphosphorylcholine (CDP-choline) pathway common to the synthesis of both phospholipids (Keidel and Gluck, '75). Increased choline incorporation into PC prior to breathing has also been observed in the mammalian fetal lung in vitro (Weinhold, '68; Weinhold et al., '73; Maniscalco et al.,'78), and was due to increased activity of enzymes in this pathway (Rooney '79; Farrell and Ulane, '81). Recently, Compton and Goeringer ('81) observed increased incorporation of choline into $\mathrm{PC}$ in lung slices from embryonic chickens prior to breathing, and they also noted increased activity of choline kinase in the CDP-choline pathway (Compton and Goeringer, '80). Our study revealed the actual synthetic rate of $\mathrm{PC}$ and Sphingo, by correcting for differences in choline pool size and specific activity (Table 6). Increased synthesis of these lipids occurred in parallel with a reduction in choline pool size (Table 5). Although the specific activity of the choline pool was elevated in day 19 lung slices, the greater activity accounted for only $42 \%$ of the accelerated rate of incorporation of label into PC and Sphingo (Table 6). DSPC was by far the predominant cholinephospholipid synthesized de novo in the embryonic avian lung. After correction for differences in choline specific activity, the rate of ${ }^{14} \mathrm{C}-\mathrm{PC}$ synthesis in day 19 lung slices was increased $24 \%$ compared with 14-day embryos (Table 6). The synthetic rate of DSPC, however, was elevated by $148 \%$ over that in day 14 lung (Table 5). Other choline phospholipids containing 
saturated fatty acids, i.e., saturated Sphingo and saturated Lyso PC, accounted for only $7 \%$ of the choline incorporated. In contrast with DSPC, saturated Sphingo did not show an increased incorporation rate in the day 19 lung, even though total (saturated and unsaturated) Sphingo incorporated label at an increased rate. Since the embryonic lung has the capacity to synthesize DSPC at a high rate in vitro, it is unlikely that a major fraction of this principal surfactant lipid is transported to lung from yolk or liver. Increased choline incorporation into DSPC has also beel observed in vitro in the mammalian fetal lung prior to birth (Maniscalco et al., 78). Stimulated synthesis of DSPC in the mammal results from increased activity of lysolecithin acyltransferase and lysolecithin:lysolecithin acyltransferase (Rooney, '79), enzymes which remodel $P C$ previously synthesized from unsaturated fatty acids (Farrell and Ulane, '81). The existence of a PC-remodeling system in the lung of the chicken and increased activity in remodeling enzymes prior to breathing remain to be established. However, the large difference between the rate of incorporation of ${ }^{14} \mathrm{C}$-choline into total lung PC and its DSPC component at day 19 compared with day 14 suggests a rapid conversion of PC into DSPC in the older embryos.

The avian lung seems quite similar to the mammalian lung in those aspects of lipid composition and biosynthesis closely related to production of surfactant. As in the mammal, juvenile chicken pulmonary tissue, lamellar bodies, and lavage were enriched in PC and DSPC. Most DSPC in the avian lung was composed of dipalmitoyl PC, the most potent surface-active phospholipid of mammalian surfactant. This lipid can be synthesized by the lung of the chicken embryo. The specific stimulation of DSPC biosynthesis prior to breathing duplicates the ontogenetic pattern observed in mammalian fetal lung.

\section{ACKNOWLEDGMENTS}

This work was supported by Rackham Dissertation and Faculty grants. The authors thank Dr. Dusan Baić for excellent technical advise. An earlier version of this manuscript was read by Drs. G. Nace, P. Weinhold, and T.M. Rizki. The authors also express gratitude to Ms. S. Schaerer, for typing this manuscript.

\section{LITERATURE CITED}

Ballard, P.L. (1981) Hormonal regulation of the surfactant system. In: Physiological and Biochemical Basis for Perinatal Medicine. M. Monset-Couchard and A. Minkowski, eds. Karger, Basel, pp. 42-53.

Bartlett, G.R. (1959) Phosphorous assay in column chromatography. J Biol. Chem., 234:466-468.
Bhattacharyya, G.K., and R.A. Johnson (1977) Statistical Concepts and Methods. John Wiley and Sons, New York. Biezenski, J.J. (1964) Quantitation and preparation of phospholipids by elution following improved thin layer chromatography separation. Fed. Proc., 23:503.

Compton, S.K., and G.C. Goeringer (1980) Choline kinase and ethanolamine kinase activity in the developing chick lung. Am. Rev. Respir. Dis., 121:328.

Compton, S.K, and G.C. Goeringer (1981) Lung development in the chick embryo. I. Phosphatidylcholine synthesis in the developing chick lung. Podiatr. Res., 15:866-869.

Dameron, F., and L. Marin (1970) Mode de formation des inclusions lamellaires dans le poumon embryonnaire de poulet. Z. Zellforsch., 110:72-84.

Doneen, B.A. (1981) Effects of hypophysectomy and corticosterone acetate treatment on hepatic lipid composition in the chick (Gallus domesticus) embryo. Gen. Comp. Endocrinol., 43:284-291.

Duncker, H.R. (1971) The lung air sac system of birds. A contribution to the functional anatomy of the respiratory apparatus. Adv. Anat. Embryol. Cell Biol., 45(6):1-171.

Duncker, H.R. (1978) Development of the avian respiratory and circulatory systems. In: Respiratory Function in Birds, Adult and Embryonic. J. Piiper, ed. SpringerVerlag, New York, pp. 260-273.

Farrell, P.M., and Ulane, R.E. (1981) The regulation of phospholipid metabolism in the developing fetus. In: Physiological Biochemical Basis for Perinatal Medicine. M. Monset-Couchard, and A. Minkowski, eds. Karger. Basel, pp. 30-41.

Folch, J., M. Lees, and G.H. Sloane-Stanley (1957) A simple method for the isolation and purification of total lipids from animal tissues. J. Biol. Chem., 226:497-509.

Fujiwara, T., F.H. Adams, M. Nozaki, and G.B. Dermer (1970) Pulmonary surfactant phospholipids from turkey lung: Comparison with rabbit lung. Am. J. Physiol., 218:218-225.

Harlan, W.R., J.H. Margraf, and S.I. Said (1966) Pulmonary lipid composition of species with and without surfactant. Am. J. Physiol., 211:855-861.

Heath, M.F., and W. Jacobson (1976) Phospholipases $A_{1}$ and $A_{2}$ in lamellar inclusion bodies onf the alveolar epithelium of rabbit lung. Biochim. Biophys. Acta, 441:443-452.

Hirsch, J.G., and M.E. Fedorko (1968) Ultrastructure of human leukocytes after simultaneous fixation with glutaraldehyde and osmium tetroxide and "postfixation" in uranyl acetate. J. Cell Biol., 38:615-627.

Hitchcock, K.R. (1980) Lung development and the pulmonary surfactant system: Hormonal influences. Anat. Rec., 198:13-14.

Keidel, W.M., and L. Gluck (1975) Lipid biochemistry and biochemical development of the lung. In: Pulmonary Physiology of the Fetus, Newborn and Child. E. Scarpelli, ed. Lea and Febiger, Philadelphia, pp. 96-115.

King, R.J. (1974) The surfactant system of the lung. Fed Proc., 33:2238-2247.

Lambson, R.O., and J.E. Cohn (1968) Ultrastructure of the lung of the goose and its lining of surface material. Am. J. Anat., 122:631-650.

Levine, O.R., and R.B. Mellins (1975) Liquid balance in the lung and pulmonary edema. In: Pulmonary Physiology of the Fetus, Newborn and Child. E. Scarpelli, ed. Lea and Febiger, Philadelphia, pp, 239-258.

Lowry, O.H., N.J. Rosebrough, A.L. Farr, and R.J. Randall (1951) Protein measurement with the folin phenol reagent. J. Biol. Chem., 193:265-275.

Luddy, E.F., R.A. Barford, and R.W. Riemenschneider (1960) Direct conversion of lipid components to their fatty acid methyl esters. J. Am. Oil Chem. Soc., 37:447-451. 
Maniscalco, W.M., C.M. Wilson, I. Gross, L. Gobran, S.A. Rooney, and J.B. Warshaw (1978) Development of glycogen and phospholipid metabolism in fetal and newborn rat lung. Biochim. Biophys. Acta, 530:333-346.

Marin, L., F. Dameron, B. Bruner, and C. Tordet (1979) Composition en phospholipides et en acides gras des inclusions lamellaires isolées à partir de poumons de Poulets à différents stades du développement. C.R. Acad. Sci. [D] (Paris), 289:1291-1294.

Marin, L., C. Tordet, and F. Dameron (1978) The endocrine control of embryonic lung maturation in the chicken. I. Morphological and biochemical differentiation of lungs after "in ovo" decapitation. Anat. Embryol., 152:223-234.

Mason, R.J., J. Nellenbogen, and J.A. Clements (1976) Isolation of dissaturated phosphatidylcholine with osmium tetroxide. J. Lipid Res., 17:281-284.

Pattle, R.E. (1965) Surface lining of Jung alveoli. Physiol. Rev., 45:48-79.

Pattle, R.E. (1978) Lung surfactant and lung lining in birds. In: Respiratory Function in Birds, Adult and Embryonic. J. Piiper, ed. Springer-Verlag, New York, pp. 23-32.

Petrik, P., and B. Riedel (1968a) A continuous osmiophilic noncellular membrane at the respiratory surface of the lungs of fetal chickens and of young chicks. Lab. Invest., 18:54-62.

Petrik, P. and B. Riedel (1968b) An osmiophilic bilaminar lining film at the respiratory surfaces of avian lungs. $Z$. Zellforsch., 88:204-219.

Rooney, S.A. (1979) Biosynthesis of lung surfactant during fetal and early postnatal development. Trends Biochem.
Sci., 5:189-191

Shea, P.A., and M.H. Aprison (1973) An enzymatic method for measuring picomole quantities of acetylcholine and choline in CNS tissue. Anal. Biochem., 56:165-177.

Smith, B.T., and W.G. Bogues (1980) Effects of drugs and hormones on lung maturation in experimental animal and man. Pharmacol. Ther., 9:51-74.

Tordet, C., and L. Marin (1976) Lipid and phospholipid content and fatty acid composition of the chick lung during embryonic development. Experientia, 32:628-630.

Touchstone, J.C., J.C. Chen, and K.M. Beaver (1980) Improved separation of phospholipids in thin layer chromatography. Lipids, 15(1):61-62.

Tyler, W., and J. Pangborn (1964) Laminated membrane surface and osmiophilic inclusions in avian lung epithelium. J. Cell Biol., 20:157-164.

Van Golde, L.M.G. (1976) State of the art. Metabolism of phospholipids in the lung. Am. Rev. Respir. Dis., 114:977-1000.

Weinhold, P.A. (1968) Biosynthesis of phosphatidylcholine during prenatal development of the rat lung. J. Lipid Res., 9:262-266.

Weinhold, P.A., R. Sanders, and W. Stern (1973) Regulation of choline phosphoglyceride synthesis during lung development in the rat. IN: Respiratory Distress Syndrome. C.A. Villee, D.B. Villee, and J. Zuckerman, eds. Academic Press, New York, pp. 29-45.

Williams, M.C. (1977) Development of the alveolar structure of the fetal rat in late gestation. Fed. Proc. $36: 2653-2659$. 